\title{
Effects of dietary hatchery by-products on growth performance, relative organ weight, plasma measurements, immune organ index, meat quality, and tibia characteristics of broiler chickens
}

\author{
Won Jun Choi ${ }^{1}$, Jong Hyuk Kim ${ }^{1}$, Gi Ppeum Han ${ }^{1}$, Chan Ho Kwon ${ }^{1}$, and Dong Yong Kil ${ }^{1}$ *
}

\author{
* Corresponding Author: Dong Yong Kil \\ Tel: +82-31-670-3028, \\ E-mail: dongyong@cau.ac.kr \\ ${ }^{1}$ Department of Animal Science and \\ Technology, Chung-Ang University, Anseong \\ 17546, Korea \\ ORCID \\ Won Jun Choi \\ https://orcid.org/0000-0003-4000-990X \\ Jong Hyuk Kim \\ https://orcid.org/0000-0003-0289-2949 \\ Gi Ppeum Han \\ https://orcid.org/0000-0001-7794-2213 \\ Chan Ho Kwon \\ https://orcid.org/0000-0003-1697-4435 \\ Dong Yong Kil \\ https://orcid.org/0000-0002-9297-849X
}

Submitted Nov 5, 2020; Revised Dec 21, 2020; Accepted Dec 26, 2020
Objective: The objective of the current study was to investigate the effects of dietary hatchery by-products (HBPs) as a replacement of fish meal (FM) on growth performance, relative organ weight, plasma measurements, immune organ index, meat quality, and tibia characteristics of broiler chickens.

Methods: A total of 720 broiler chickens ( $3 \mathrm{~d}$ of age) were randomly allotted to 1 of 9 treatments with 8 replicates. Each replicate consisted of 5 male and 5 female birds. The basal diet was formulated to contain $5.0 \%$ commercial FM, whereas eight treatment diets were prepared by replacing $25 \%, 50 \%, 75 \%$, or $100 \%$ of $\mathrm{FM}$ in the basal diet with infertile eggs (IFE) or a mixture of various HBPs (MIX); therefore, the inclusion levels of IFE or MIX in the experimental diets were $1.25 \%, 2.50 \%, 3.75 \%$, or $5.00 \%$. The diets and water were provided on an ad libitum basis for $32 \mathrm{~d}$.

Results: Increasing inclusion levels of IFE as a replacement of FM in diets had no effects on growth performance, plasma measurements, immune organ index, and tibia characteristics of broiler chickens. Increasing inclusion levels of IFE in diets increased (linear, $\mathrm{p}<0.05)$ meat lightness $\left(\mathrm{L}^{*}\right)$ but decreased (linear, $\left.\mathrm{p}<0.05\right)$ meat redness $\left(\mathrm{a}^{*}\right)$. The breast meat $\mathrm{pH}$ at 1 -h postmortem was increased (linear, $\mathrm{p}<0.05$ ) by increasing inclusion levels of IFE in diets. Likewise, increasing inclusion levels of MIX in diets had no effects on growth performance, relative organ weight, plasma measurements, immune organ index, and tibia characteristics. However, increasing inclusion levels of MIX in diets increased (linear, $\mathrm{p}<0.05$ ) 1 -h postmortem $\mathrm{pH}$ but decreased (linear, $\mathrm{p}<0.05$ ) 24 -h postmortem $\mathrm{pH}$ of breast meat. Increasing inclusion levels of MIX in diets decreased (linear, $\mathrm{p}<0.05$ ) thiobarbituric acid reactive substances values of breast meat.

Conclusion: Both IFE and MIX are suitable alternatives to FM as protein ingredients in broiler diets.

Keywords: Animal Protein Ingredient; Broiler Chicken; Fish Meal; Growth Performance; Hatchery By-products; Infertile Eggs

\section{INTRODUCTION}

Poultry diets are formulated primarily with various vegetable ingredients, which are relatively cheap but contain the less bioavailable nutrients than animal-derived ingredients and purified nutrients. Therefore, despite their high price, animal protein sources such as fish meal (FM) are often added to poultry diets, especially for broiler chickens, to satisfy the essential amino acid (AA) requirements. Feed cost constitutes the largest portion of the total cost of poultry production, and therefore, the identification and increased use of potential and inexpensive animal protein sources would significantly improve economic 
outcomes of the poultry industry [1].

The Korean poultry industry produces more than 4,000 tons of hatchery by-products (HBPs) every year. These HBPs include infertile eggs (IFE), unhatched eggs (UHE), low grade and dead chicks (LDC), and eggshells (ES) [2]. In commercial hatcheries, IFE are typically collected at the middle of the hatching process (e.g., examination of fertilization), whereas UHE, LDC, and ES are mostly collected at the end of the hatching process. The collected UHE, LDC, and ES are mixed to produce the final HBPs with or without inclusion of IFE. Currently, most HBPs produced in South Korea are composted as a fertilizer, and the raising environmental concerns necessitate an alternative solution for the use of HBPs. The HBPs contain high amounts of available nutrients such as AAs, calcium (Ca), and phosphorus (P) for animals. Several previous experiments have reported that the HBPs can be used as economical and potential protein ingredients for poultry diets $[1,3]$. However, few studies have directly evaluated a mixture of HBPs (MIX) as an alternative to FM, which is widely used as an animal protein ingredient in poultry diets. In addition, IFE can be collected separately from MIX, and thus, IFE is likely another potential source of animal protein. However, there is very limited information regarding the nutritive value of IFE and MIX in broiler diets, especially compared with FM.

Accordingly, the objective of the present study was to investigate the effects of dietary IFE and MIX (a conventional mixture of IFE, UHE, LDC, and ES) as a replacement of FM on growth performance, relative organ weight, plasma measurements, immune organ index, meat quality, and tibia characteristics of broiler chickens.

\section{MATERIALS AND METHODS}

\section{Animals, experimental design, and diets}

The protocol for the current experiment was reviewed and approved by the Institutional Animal Care and Use Committee at Chung-Ang University (IACUC No. 2018-00136). In total, 720 Ross 308 broiler chicks ( $1 \mathrm{~d}$ of age) were obtained from a local hatchery (Dongsan broiler hatchery, Cheonan, Korea). The chicks were fed a commercial pellet starter diet until $3 \mathrm{~d}$ of age. At the $3 \mathrm{~d}$ of age, chicks with an average initial body weight $(\mathrm{BW})$ of $82 \pm 2.1 \mathrm{~g}$ were allotted to 1 of 9 treatments with 8 replicates in a completely randomized design. Each replicate consisted of 5 male and 5 female birds.

The HBPs, including IFE, UHE, LDC, and ES, were separately obtained from a local hatchery (Dongsan broiler hatchery, Cheonan, Korea). A mixture of assorted HBPs (designated MIX) was produced with a composition of 55\% IFE, 10\% UHE, 10\% LDC, and 25\% ES, which was based on the consideration of typical production ratio of each HBP in the commercial hatchery [2]. The IFE and MIX samples were ground using a meat chopper (MN-225, Hankook Fujee, Hwaseong, Korea) and dried at $50^{\circ} \mathrm{C}$ for $24 \mathrm{~h}$ in a vertical convention oven (LDO-630F, Daihan Labtech, Namyangju, Korea) to ensure that they contained less than $2.0 \%$ water. The commercial FM was also prepared for diet formulation. The analyzed nutrient concentrations of IFE, MIX, and FM are presented in Table 1 .

The basal diet for the control group was formulated to contain 5.0\% FM, which is close to the maximum inclusion levels of FM in the commercial broiler diet. Eight treatment diets were prepared by replacing $25 \%, 50 \%, 75 \%$, or $100 \%$ of FM with either IFE or MIX. Therefore, the actual inclusion levels of IFE or MIX in the experimental diets were $1.25 \%, 2.50 \%$, $3.75 \%$, or $5.00 \%$. All nutrient concentrations of 9 treatments diets (Tables 2, 3) were formulated to be identical and satisfied for nutrient requirements of growing and finishing broiler chickens [4]. The experimental diets and water were provided on an ad libitum basis for $32 \mathrm{~d}$ from $3 \mathrm{~d}$ to $35 \mathrm{~d}$ of age. The room temperature was maintained at $30^{\circ} \mathrm{C}$ at the start of the experiment and then gradually decreased to $24^{\circ} \mathrm{C}$ as recommended by the Ross manual [4]. A 23-h lighting schedule was applied during the experimental period. The body weight gain (BWG) and feed intake (FI) were measured when the chickens were $35 \mathrm{~d}$ old. The mortality was recorded daily. The feed conversion ratio was calculated by dividing FI (kg) by BWG $(\mathrm{kg})$ after correcting for mortality.

\section{Sample collection and analysis}

At the end of experiment ( $35 \mathrm{~d}$ of age), the individual weights of all broiler chickens were recorded. The broiler chickens,

Table 1. Energy and nutrient composition of fish meal (FM), infertile eggs (IFE), and a mixture of hatchery by-products (MIX)

\begin{tabular}{lccc}
\hline Items & FM & IFE & MIX \\
\hline AME $_{n}{ }^{1)}(\mathrm{kcal} / \mathrm{kg})$ & 3,120 & 4,299 & 3,321 \\
Nutrients & \\
$\quad \mathrm{DM}(\%)$ & 90.4 & 98.3 & 98.0 \\
$\mathrm{CP}(\%)$ & 68.5 & 34.2 & 31.4 \\
$\quad$ Crude ash (\%) & 13.8 & 27.6 & 40.6 \\
$\quad$ Calcium (\%) & 3.1 & 8.9 & 17.2 \\
$\quad$ Phosphorus (\%) & 2.3 & 0.5 & 0.3 \\
Total amino acid ${ }^{3)}(\%)$ & & & \\
$\quad$ Lysine & 4.6 & 2.3 & 1.9 \\
$\quad$ Methionine+cysteine & 2.2 & 1.8 & 1.8 \\
$\quad$ Threonine & 2.6 & 1.8 & 1.5 \\
$\quad$ Tryptophan & 0.6 & 0.4 & 0.4
\end{tabular}

$\mathrm{AME}_{n}$, nitrogen-corrected apparent metabolizable energy; DM, dry matter; CP, crude protein; AA, amino acid.

1) The value for $A M E_{n}$ of FM was adopted from INRA [35], whereas the values for $\mathrm{AME}_{n}$ of IFE and MIX were measured in our previous experiment [38].

2) Nutrient concentrations were analyzed using AOAC methods [39].

3) AA concentrations were analyzed for IFE and MIX, whereas AA concentrations for FM were adopted from INRA [35]. 
Table 2. Composition and nutrient concentration of the experimental diets from $3 \mathrm{~d}$ to $21 \mathrm{~d}$ of age

\begin{tabular}{|c|c|c|c|c|c|c|c|c|c|}
\hline \multirow{2}{*}{ Items } & \multirow{2}{*}{ Control } & \multicolumn{4}{|c|}{ Inclusion levels of IFE (\%) } & \multicolumn{4}{|c|}{ Inclusion levels of MIX (\%) } \\
\hline & & 1.25 & 2.50 & 3.75 & 5.00 & 1.25 & 2.50 & 3.75 & 5.00 \\
\hline \multicolumn{10}{|l|}{ Ingredients (\%) } \\
\hline Soybean meal (46\% CP) & 30.89 & 29.49 & 30.36 & 31.22 & 32.08 & 29.53 & 30.47 & 31.35 & 32.21 \\
\hline Corn gluten meal & 0.50 & 2.00 & 2.00 & 2.00 & 2.00 & 2.00 & 2.00 & 2.00 & 2.01 \\
\hline Tallow & 3.98 & 3.14 & 2.95 & 2.79 & 2.60 & 3.24 & 3.14 & 3.03 & 2.80 \\
\hline IFE & - & 1.25 & 2.50 & 3.75 & 5.00 & - & - & - & - \\
\hline MIX & - & - & - & - & - & 1.25 & 2.50 & 3.75 & 5.00 \\
\hline Limestone & 1.27 & 1.11 & 0.94 & 0.78 & 0.60 & 0.83 & 0.38 & 0.00 & 0.00 \\
\hline Mono-dicalcium phosphate & 0.72 & 0.86 & 0.98 & 1.10 & 1.22 & 0.87 & 1.00 & 0.95 & 0.00 \\
\hline Potassium phosphate & 0.30 & 0.30 & 0.30 & 0.30 & 0.30 & 0.30 & 0.30 & 0.47 & 1.49 \\
\hline Potassium carbonate & 0.59 & 0.65 & 0.63 & 0.62 & 0.61 & 0.64 & 0.63 & 0.53 & 0.00 \\
\hline L-tryptophan (19.6\%) & 0.01 & 0.04 & 0.03 & 0.02 & 0.02 & 0.04 & 0.03 & 0.02 & 0.00 \\
\hline Salt & 0.20 & 0.20 & 0.20 & 0.20 & 0.20 & 0.20 & 0.20 & 0.20 & 0.20 \\
\hline Choline chloride & 0.10 & 0.10 & 0.10 & 0.10 & 0.10 & 0.10 & 0.10 & 0.10 & 0.10 \\
\hline Sodium bicarbonate & 0.10 & 0.10 & 0.10 & 0.10 & 0.10 & 0.10 & 0.10 & 0.10 & 0.10 \\
\hline Cocciodiostat & 0.10 & 0.10 & 0.10 & 0.10 & 0.10 & 0.10 & 0.10 & 0.10 & 0.10 \\
\hline Vitamin premix ${ }^{1)}$ & 0.25 & 0.25 & 0.25 & 0.25 & 0.25 & 0.25 & 0.25 & 0.25 & 0.25 \\
\hline Mineral premix ${ }^{2)}$ & 0.25 & 0.25 & 0.25 & 0.25 & 0.25 & 0.25 & 0.25 & 0.25 & 0.25 \\
\hline Total & 100 & 100 & 100 & 100 & 100 & 100 & 100 & 100 & 100 \\
\hline \multicolumn{10}{|c|}{ Calculated energy and nutrient concentration } \\
\hline $\mathrm{AME}_{\mathrm{n}}(\mathrm{kcal} / \mathrm{kg})$ & 3,050 & 3,050 & 3,050 & 3,050 & 3,050 & 3,050 & 3,050 & 3,050 & 3,050 \\
\hline $\mathrm{CP}(\%)$ & 22.25 & 22.25 & 22.25 & 22.25 & 22.25 & 22.25 & 22.25 & 22.25 & 22.25 \\
\hline
\end{tabular}

CP, crude protein; FM, fish meal; IFE, infertile eggs; MIX, a mixture of hatchery by-products; $\mathrm{AME}_{n}$, nitrogen-corrected apparent metabolizable energy.

1) Provided per kg of the complete diet: vitamin $A, 10,000 \mathrm{IU}$ (retinyl acetate); vitamin $D_{3}, 4,500$ IU; vitamin $\mathrm{K}_{3}, 3.0$ mg (menadione dimethpyrimidinol); vitamin $B_{1}, 2.50$ mg; vitamin $B_{2}, 6.50$ mg; vitamin $B_{6}, 3.20$ mg; vitamin $B_{12}, 18.0 \mu$ g; folic acid, 1.9 mg; biotin, $180 \mu$; niacin, 60 mg.

2) Provided per kg of the complete diet: iron, $72 \mathrm{mg}\left(\mathrm{FeSO}_{4}\right)$; zinc, $120 \mathrm{mg}\left(\mathrm{ZnSO}_{4}\right)$; manganese, $144.0 \mathrm{mg}(\mathrm{MnO})$; copper, $\left.19.0 \mathrm{mg}(\mathrm{CuSO})_{4}\right)$; cobalt, 1,200 $\mu \mathrm{gg}$ $\left(\mathrm{CoSO}_{4}\right)$; selenium, $360 \mu \mathrm{g}\left(\mathrm{Na}_{2} \mathrm{SeO}_{3}\right)$; iodine, $1.5 \mathrm{mg}\left[\mathrm{Ca}\left(\mathrm{IO}_{3}\right)_{2}\right]$.

which is the closest to average weight of the replicated cage, were euthanized via $\mathrm{CO}_{2}$ asphyxiation. Blood samples from each bird were collected via heart puncture into a $10-\mathrm{mL}$ vacutainer tube containing sodium heparin (BD, Franklin Lakes, $\mathrm{NJ}$, USA) and then centrifuged at $3,000 \times \mathrm{g}$ at $4^{\circ} \mathrm{C}$ for $20 \mathrm{~min}$ to obtain the plasma. The plasma samples were stored at $-20^{\circ} \mathrm{C}$ before further analysis. The concentrations of albumin, alanine aminotransferase (ALT), aspartate aminotransferase (AST), creatinine, glucose, total protein, and total glyceride in the plasma were analyzed using a HITACHI 7020 automatic analyzer (Hitachi, Tokyo, Japan).

The liver, kidney, small intestine, and gizzard were collected, and their relative weight (the weight as a percentage of the total BW) were calculated. The immune organs such as thymus, spleen, and bursa of Fabricius were also collected and weighed. The values for immune organ index were calculated by the following equation: (immune organ weight $[\mathrm{g}]$ /BW [g] $) \times 1,000$ [5].

The right portion of the breast meat was detached from the sternum for meat quality analyses. The color of breast meat was measured directly postmortem using a colorimeter (model CR-10, Konica Minolta, Tokyo, Japan) with the lightness $\left(\mathrm{L}^{\star}\right)$, redness $\left(\mathrm{a}^{*}\right)$, and yellowness $\left(\mathrm{b}^{*}\right)$ values of the meat surface being recorded. The breast meat was then weighed and divided into 4 parts, which were respectively used to measure $\mathrm{pH}$ at $1 \mathrm{~h}$ and $24 \mathrm{~h}$ postmortem, water holding ca- 
Table 3. Composition and nutrient concentration of the experimental diets from $22 \mathrm{~d}$ to $35 \mathrm{~d}$ of age

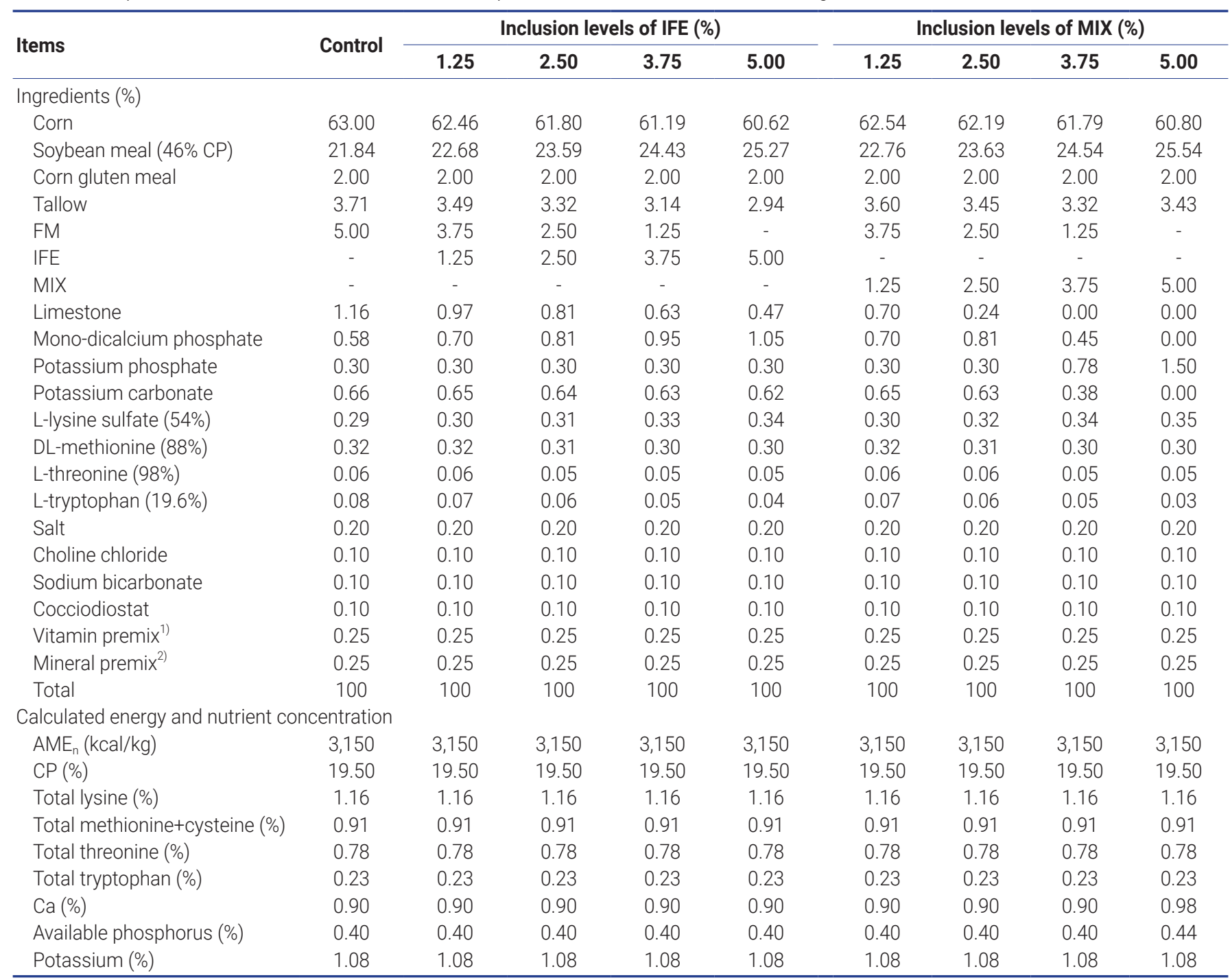

$\mathrm{CP}$, crude protein; $\mathrm{FM}$, fish meal; IFE, infertile eggs; $\mathrm{MIX}$, a mixture of hatchery by-products; $\mathrm{AME}_{n}$, nitrogen-corrected apparent metabolizable energy.

1) Provided per kg of the complete diet: vitamin $A, 10,000 \mathrm{IU}$ (retinyl acetate); vitamin $\mathrm{D}_{3}, 4,500 \mathrm{IU}$; vitamin $\mathrm{K}_{3}, 3.0$ mg (menadione dimethpyrimidinol); vitamin $B_{1}, 2.50$ mg; vitamin $B_{2}, 6.50$ mg; vitamin $B_{6}, 3.20$ mg; vitamin $B_{12}, 18.0 \mu$ g; folic acid, 1.9 mg; biotin, $180 \mu$ g; niacin, 60 mg.

${ }^{2)}$ Provided per $\mathrm{kg}$ of the complete diet: iron, $72 \mathrm{mg}\left(\mathrm{FeSO}_{4}\right)$; zinc, $120 \mathrm{mg}\left(\mathrm{ZnSO}_{4}\right)$; manganese, $144.0 \mathrm{mg}(\mathrm{MnO})$; copper, $19.0 \mathrm{mg}\left(\mathrm{CuSO}_{4}\right)$; cobalt, 1,200 $\mu \mathrm{g}$ $\left(\mathrm{CoSO}_{4}\right)$; selenium, $360 \mu \mathrm{g}\left(\mathrm{Na}_{2} \mathrm{SeO}_{3}\right)$; iodine, $1.5 \mathrm{mg}\left[\mathrm{Ca}\left(\mathrm{IO}_{3}\right)_{2}\right]$.

pacity (WHC) at $24 \mathrm{~h}$ postmortem, and thiobarbituric acid reactive substances (TBARS) at $7 \mathrm{~d}$ postmortem. The 4 pieces of breast meat were stored at $4^{\circ} \mathrm{C}$ until further analysis. The meat $\mathrm{pH}$ was measured using a $\mathrm{pH}$ meter (Hanna Instruments, Nusfalau, Romania) at a depth of $1 \mathrm{~cm}$. The WHC of breast meat was measured at $24 \mathrm{~h}$ postmortem according to the method described by Lee et al [6]. A portion of meat samples $(1.5 \mathrm{~g})$ was centrifuged at the speed of $3,000 \times \mathrm{g}$ at $5^{\circ} \mathrm{C}$ for $15 \mathrm{~min}$. The WHC (\%) was calculated as ([weight before centrifugation - weight after centrifugation]/weight before centrifugation) $\times 100$ [6]. The TBARS values of breast meat were measured as an indicator of lipid oxidation, following the method described by Lee et al [6]. Firstly, $5 \mathrm{~g}$ of the meat sample were placed in a $50-\mathrm{mL}$ test tube with $15 \mathrm{~mL}$ of deionized distilled water and then homogenized in ice using an electric homogenizer (Tissue Tearor; Biospec, Bartlesville, OK, USA). Then, $1 \mathrm{~mL}$ of homogenized solution was placed in a disposable test tube $(13 \mathrm{~mm} \times 100 \mathrm{~mm})$ with 2 $\mathrm{mL}$ of thiobarbituric/trichloroacetic acid and $50 \mu \mathrm{L}$ of 100 $\mathrm{mL} / \mathrm{L}$ butylated hydroxyanisole. The mixture was incubated in boiling water for $15 \mathrm{~min}$ to develop the color. The mixture was cooled in an ice bath for $10 \mathrm{~min}$ and then vortexed. The mixture was centrifuged at 2,000×g for $15 \mathrm{~min}$, and then the supernatant was collected. Finally, the absorbance of the supernatant at $531 \mathrm{~nm}$ was determined using a microplate reader (Spectramax 190, Molecular Devices, Sunnyvale, CA, USA).

Both right and left tibias were collected to analyze bone 
characteristics. The muscle attached to the tibias was removed. The concentrations of $\mathrm{Ca}, \mathrm{P}$, and ash in the right tibia were analyzed, whereas the left tibia was used to measure the breaking strength. The right tibia was dried at $100^{\circ} \mathrm{C}$ for $24 \mathrm{~h}$ in a drying oven and then placed in a Soxhlet apparatus for $48 \mathrm{~h}$ to remove the fat using ethyl ether as a solvent. Afterwards, the right tibia was dried again at $100^{\circ} \mathrm{C}$ for $24 \mathrm{~h}$ in a drying oven and then ground to powder. Ground samples were ashed in a muffle furnace at $600^{\circ} \mathrm{C}$ for $24 \mathrm{~h}$ to measure tibia ash concentrations $[7,8]$. The $\mathrm{Ca}$ and $\mathrm{P}$ concentrations in the ash of the right tibia were measured using an inductively coupled plasma spectrometer (Optima 5300 DV, Perkin Elmer, Shelton, CT, USA) as described by Kurtoğlu et al [9]. Breaking strength of the left tibia was analyzed using a TAHDi texture analyzer (Stable Micro Systems, Surrey, UK) according to the method described by Shaw et al [10].

\section{Statistical analysis}

All data were analyzed using analysis of variance in a completely randomized design using the MIXED procedure (SAS Institute Inc., Cary, NC, USA). All data were checked for outliers and normal distribution using the UNIVARIATE procedure of SAS (SAS Institute Inc., USA). One outlier was identified and removed from the final data analysis. The replicate was used as an experimental unit for all measurements. There were 9 experimental diets in this study, including 1 basal diet, 4 diets containing IFE, and 4 diets containing MIX. In order to evaluate individual IFE and MIX as alternatives to FM, IFE and MIX treatments were analyzed separately, with each evaluation involving 5 experimental diets (1 basal diet and 4 treatment diets containing different inclusion levels of IFE or MIX). The LSMEANS procedure was used to calculate treatment means and the PDIFF option of SAS was used to separate the means if the difference was significant. Orthogonal polynomial contrasts test was also used to determine the linear and quadratic effects of increasing inclusion levels of IFE or MIX as a replacement of FM in diets. Significance for statistical tests was set at $\mathrm{p}<0.05$.

\section{RESULTS AND DISCUSSION}

\author{
Nutrient composition of infertile eggs and hatchery by- \\ product mixture
}

The proximate and AA compositions of the IFE and MIX used in this experiment are presented in Table 1. The concentrations of crude protein (CP), Ca, and P in the MIX were comparable to previous results of a mixture of HBPs [11]. However, other studies have used HBP mixtures with different ratios of each HBP, leading to differences in nutrient concentrations comparing with HBPs used in this study [12]. The concentrations of $\mathrm{CP}$ and $\mathrm{P}$ were similar between IFE and MIX, whereas MIX had a greater concentration of Ca than IFE because of the inclusion of UHE, LDC, and ES, which contained high amounts of Ca. Based on the concentrations of CP and Ca, both IFE and MIX can be good sources of protein and $\mathrm{Ca}$ for broiler diets.

\section{Growth performance}

Increasing inclusion levels of IFE or MIX from $0 \%$ to $5.0 \%$ as a replacement of FM in diets had no effects on growth performance of broiler chickens (Tables 4,5), which indicates that both IFE and MIX are suitable replacements of FM in broiler diets if the diets are formulated to keep the constant energy and nutrient concentrations. A similar result was observed by Rasool et al [13] who used a control diet containing 12\% FM and found that 100\% replacement of FM with HBPs had no adverse effects on growth performance of broiler chicks. The reason for these results is that both FM and HBPs (i.e., IFE and MIX) are animal protein sources and contain high amounts of available essential AAs and minerals for broiler chickens [14].

\section{Plasma measurements}

Plasma measurements, including albumin, ALT, AST, creatinine, glucose, total protein, and total glyceride were not influenced by increasing inclusion levels of IFE or MIX as a replacement of FM in broiler diets (Tables 6, 7). The plasma concentrations of albumin, ALT, and AST have been rou-

Table 4. Effect of increasing inclusion levels of infertile eggs (IFE) as a replacement of fish meal (FM) in diets on growth performance of broiler chickens $^{1), 2)}$

\begin{tabular}{|c|c|c|c|c|c|c|c|c|c|}
\hline \multirow{2}{*}{ Items } & \multicolumn{5}{|c|}{ Inclusion levels of IFE ${ }^{3)}(\%)$} & \multirow{2}{*}{ SEM } & \multicolumn{3}{|c|}{ p-value ${ }^{4)}$} \\
\hline & 0.00 & 1.25 & 2.50 & 3.75 & 5.00 & & $\mathbf{T}$ & $\mathbf{L}$ & $\mathbf{Q}$ \\
\hline BWG (kg) & 2.01 & 2.05 & 2.02 & 1.99 & 2.03 & 0.045 & 0.92 & 0.88 & 0.94 \\
\hline $\mathrm{FI}(\mathrm{kg})$ & 3.05 & 3.08 & 3.07 & 3.05 & 3.08 & 0.049 & 0.98 & 0.72 & 0.95 \\
\hline $\mathrm{FCR}(\mathrm{kg} / \mathrm{kg})$ & 1.51 & 1.50 & 1.53 & 1.53 & 1.52 & 0.024 & 0.91 & 0.56 & 0.81 \\
\hline
\end{tabular}

SEM, standard error of the mean; BWG, body weight gain; Fl, feed intake; FCR, feed conversion ratio.

1) Data are least squares means of 8 observations per treatment.

2) Diets were fed to birds for $32 \mathrm{~d}$ from 3 to $35 \mathrm{~d}$ of age.

3) IFE was included at replacing levels of $0 \%, 25 \%, 50 \%, 75 \%$, or $100 \%$ with $5.0 \%$ FM in the basal diet.

4) $T$, overall effects of treatments; $L$, linear effects of increasing replacement levels of IFE in diets; Q, quadratic effects of increasing replacement levels of IFE in diets. 
Table 5. Effect of increasing inclusion levels of a mixture of hatchery by-products (MIX) as a replacement of fish meal (FM) in diets on growth performance of broiler chickens ${ }^{1), 2)}$

\begin{tabular}{|c|c|c|c|c|c|c|c|c|c|}
\hline \multirow{2}{*}{ Items } & \multicolumn{5}{|c|}{ Inclusion levels of MIX ${ }^{3)}(\%)$} & \multirow{2}{*}{ SEM } & \multicolumn{3}{|c|}{ p-value ${ }^{4)}$} \\
\hline & 0.00 & 1.25 & 2.50 & 3.75 & 5.00 & & $\mathbf{T}$ & $\mathbf{L}$ & $\mathbf{Q}$ \\
\hline BWG (kg) & 2.01 & 1.93 & 2.06 & 2.03 & 1.97 & 0.042 & 0.23 & 0.90 & 0.46 \\
\hline $\mathrm{FI}(\mathrm{kg})$ & 3.05 & 2.98 & 3.21 & 3.11 & 3.08 & 0.053 & 0.05 & 0.24 & 0.22 \\
\hline FCR $(\mathrm{kg} / \mathrm{kg})$ & 1.51 & 1.54 & 1.56 & 1.53 & 1.56 & 0.019 & 0.43 & 0.17 & 0.65 \\
\hline
\end{tabular}

SEM, standard error of the mean; BWG, body weight gain; Fl, feed intake; FCR, feed conversion ratio.

1) Data are least squares means of 8 observations per treatment.

2) Diets were fed to birds for $32 \mathrm{~d}$ from 3 to $35 \mathrm{~d}$ of age.

${ }^{3)}$ MIX was included at replacing levels of $0 \%, 25 \%, 50 \%, 75 \%$, or $100 \%$ with $5.0 \%$ FM in the basal diet.

${ }^{4)} \mathrm{T}$, overall effects of treatments; $L$, linear effects of increasing replacement levels of MIX in diets; $Q$, quadratic effects of increasing replacement levels of MIX in diets.

Table 6. Effect of increasing inclusion levels of infertile eggs (IFE) as a replacement of fish meal (FM) in diets on the plasma measurements of broiler chickens ${ }^{1)}$

\begin{tabular}{|c|c|c|c|c|c|c|c|c|c|}
\hline \multirow{2}{*}{ Items } & \multicolumn{5}{|c|}{ Inclusion levels of IFE ${ }^{2)}(\%)$} & \multirow[t]{2}{*}{ SEM } & \multicolumn{3}{|c|}{ p-value ${ }^{3)}$} \\
\hline & 0.00 & 1.25 & 2.50 & 3.75 & 5.00 & & $\mathbf{T}$ & $\mathbf{L}$ & $\mathbf{Q}$ \\
\hline Albumin (g/dL) & 1.03 & 1.06 & 1.11 & 1.05 & 1.09 & 0.040 & 0.67 & 0.40 & 0.51 \\
\hline $\operatorname{ALT}(U / L)$ & 1.79 & 1.71 & 2.31 & 2.00 & 1.69 & 0.531 & 0.91 & 0.96 & 0.49 \\
\hline $\operatorname{AST}(\mathrm{U} / \mathrm{L})$ & 338 & 362 & 335 & 323 & 310 & 32.9 & 0.85 & 0.37 & 0.64 \\
\hline Creatinine (mg/dL) & 0.30 & 0.31 & 0.31 & 0.23 & 0.27 & 0.038 & 0.57 & 0.24 & 0.86 \\
\hline Glucose (mg/dL) & 293 & 277 & 281 & 251 & 299 & 20.7 & 0.57 & 0.81 & 0.24 \\
\hline Total protein (g/dL) & 3.14 & 3.06 & 3.12 & 3.22 & 2.89 & 0.150 & 0.62 & 0.48 & 0.41 \\
\hline Total glyceride $(\mathrm{mg} / \mathrm{dL})$ & 22.03 & 23.04 & 29.88 & 34.74 & 21.21 & 4.340 & 0.17 & 0.47 & 0.07 \\
\hline
\end{tabular}

SEM, standard error of the mean; ALT, alanine aminotransferase; AST, aspartate aminotransferase.

1) Data are least squares means of 8 observations per treatment.

2) IFE was included at replacing levels of $0 \%, 25 \%, 50 \%, 75 \%$, or $100 \%$ with $5.0 \%$ FM in the basal diet.

${ }^{3)} \mathrm{T}$, overall effects of treatments; $L$, linear effects of increasing replacement levels of IFE in diets; Q, quadratic effects of increasing replacement levels of IFE in diets.

Table 7. Effect of increasing inclusion levels of a mixture of hatchery by-products (MIX) as a replacement of fish meal (FM) in diets on the plasma measurements of broiler chickens ${ }^{1)}$

\begin{tabular}{|c|c|c|c|c|c|c|c|c|c|}
\hline \multirow{2}{*}{ Items } & \multicolumn{5}{|c|}{ Inclusion levels of $\mathrm{MIX}^{2)}(\%)$} & \multirow{2}{*}{ SEM } & \multicolumn{3}{|c|}{ p-value ${ }^{3)}$} \\
\hline & 0.00 & 1.25 & 2.50 & 3.75 & 5.00 & & $\mathrm{~T}$ & $\mathbf{L}$ & $\mathbf{Q}$ \\
\hline Albumin (g/dL) & 1.03 & 0.98 & 1.12 & 1.05 & 1.08 & 0.038 & 0.15 & 0.15 & 0.81 \\
\hline $\operatorname{ALT}(U / L)$ & 1.79 & 1.33 & 1.78 & 1.56 & 1.86 & 0.459 & 0.92 & 0.79 & 0.62 \\
\hline AST $(U / L)$ & 338 & 322 & 371 & 385 & 306 & 37.2 & 0.54 & 0.99 & 0.26 \\
\hline Creatinine (mg/dL) & 0.30 & 0.31 & 0.28 & 0.32 & 0.30 & 0.042 & 0.99 & 1.00 & 1.00 \\
\hline Glucose (mg/dL) & 293 & 258 & 296 & 276 & 280 & 18.3 & 0.59 & 0.88 & 0.77 \\
\hline Total protein $(\mathrm{g} / \mathrm{dL})$ & 3.14 & 2.96 & 3.09 & 2.77 & 3.05 & 0.147 & 0.42 & 0.43 & 0.40 \\
\hline Total glyceride $(\mathrm{mg} / \mathrm{dL})$ & 22.03 & 23.69 & 22.35 & 36.83 & 28.69 & 5.313 & 0.26 & 0.12 & 0.85 \\
\hline
\end{tabular}

SEM, standard error of the mean; ALT, alanine aminotransferase; AST, aspartate aminotransferase.

1) Data are least squares means of 8 observations per treatment.

2) MIX was included at replacing levels of $0 \%, 25 \%, 50 \%, 75 \%$, or $100 \%$ with $5.0 \%$ FM in the basal diet.

${ }^{3)} \mathrm{T}$, overall effects of treatments; L, linear effects of increasing replacement levels of MIX in diets; Q, quadratic effects of increasing replacement levels of MIX in diets.

tinely used for monitoring the liver health because those concentrations are increased when liver cells are damaged $[15,16]$. In addition, the plasma concentrations of creatinine are used for a biomarker for the renal health because creatinine in the body is mainly excreted through the kidney
[17]. The plasma concentrations of glucose, total protein, and total glycerides observed in the current experiment fell within the normal range for poultry. Therefore, both IFE and MIX appear to have no negative effects on liver and kidney functions as well as nutrient metabolism in broiler chickens. 


\section{Relative organ weight}

Increasing inclusion levels of IFE as a replacement of FM in diets had no effects on the relative weight of the breast, liver, kidney, and small intestine. The relative weight of the gizzard was increased (quadratic, $\mathrm{p}<0.05$ ) with increasing inclusion levels of IFE in the diets (Table 8). However, increasing inclusion levels of MIX had no effects on the relative weight of any of the measured organs (Table 9).

The current observations are in line with a previous study reporting no difference in breast weights among birds fed diets containing from $0 \%$ to $4.5 \%$ HBPs [18]. Likewise, Abiola et al [11] also reported that the relative liver and gizzard weights were not affected by replacing FM with HBPs in broiler diets. In addition, the values of relative weights of breast, liver, kidney, and small intestine as observed in this study fell in the normal range reported previously [19-22]. However, interestingly we found a quadratic association between increasing inclusion levels of IFE in diets and the relative gizzard weight, and the reason for this observation is not clear. Despite this unexpected result, the values for the relative gizzard weight as observed in the current experiment also remained within the normal range from $1.2 \%$ to $1.5 \%$ of $\mathrm{BW}[23,24]$, and no abnormal enlargement in the gizzard size was identified. Thus, increasing inclusion levels of IFE or MIX up to $5.0 \%$ as a replacement of FM in diets are unlikely to lead to considerable changes in the gastrointestinal growth and development of broiler chickens.

\section{Immune organ index}

There were no linear or quadratic effects of increasing inclusion levels of IFE or MIX as a replacement of FM in diets on the immune organ index (Tables 10,11). The thymus is responsible for T-lymphocyte differentiation and proliferation, whereas B-lymphocytes is matured in the bursa of Fabricius $[25,26]$. The spleen plays a role in the regulation of cellular and humoral immunity in poultry via activation of T-lymphocytes, B-lymphocytes, and macrophage [27]. Therefore, the relative development of the thymus, bursa of Fabricius, and spleen can be used to evaluate immune function and health status of poultry $[28,29]$. Therefore, our results may indicate that replacing FM with IFE or MIX up to $5.0 \%$ in diets has no adverse effects on immune function of broiler chickens.

Table 8. Effect of increasing inclusion levels of infertile eggs (IFE) as a replacement of fish meal (FM) in diets on the relative organ weight of broiler chickens ${ }^{1)}$

\begin{tabular}{|c|c|c|c|c|c|c|c|c|c|}
\hline \multirow{2}{*}{ Items ${ }^{2)}(\%)$} & \multicolumn{5}{|c|}{ Inclusion levels of IFE' $(\%)$} & \multirow{2}{*}{ SEM } & \multicolumn{3}{|c|}{ p-value $e^{4)}$} \\
\hline & 0.00 & 1.25 & 2.50 & 3.75 & 5.00 & & $\mathrm{~T}$ & $\mathbf{L}$ & $\mathbf{Q}$ \\
\hline Breast & 21.0 & 19.3 & 22.1 & 20.4 & 19.9 & 0.65 & 0.05 & 0.59 & 0.44 \\
\hline Liver & 3.0 & 2.7 & 2.8 & 2.6 & 2.5 & 0.23 & 0.63 & 0.15 & 0.84 \\
\hline Kidney & 0.6 & 0.5 & 0.6 & 0.5 & 0.6 & 0.04 & 0.58 & 0.91 & 0.27 \\
\hline Small intestine & 3.1 & 3.2 & 3.0 & 3.0 & 3.0 & 0.15 & 0.75 & 0.45 & 0.93 \\
\hline Gizzard & 1.3 & 1.3 & 1.2 & 1.3 & 1.4 & 0.05 & 0.18 & 0.16 & $<0.05$ \\
\hline
\end{tabular}

SEM, standard error of the mean.

${ }^{1)}$ Data are least squares means of 8 observations per treatment.

${ }^{2)}$ Relative organ weight $=[$ organ weight $(\mathrm{g}) /$ body weight $(\mathrm{g})] \times 100$.

3) IFE was included at replacing levels of $0 \%, 25 \%, 50 \%, 75 \%$, or $100 \%$ with $5.0 \%$ FM in the basal diet.

${ }^{4)} \mathrm{T}$, overall effects of treatments; $L$, linear effects of increasing replacement levels of IFE in diets; Q, quadratic effects of increasing replacement levels of IFE in diets.

Table 9. Effect of increasing inclusion levels of a mixture of hatchery by-products (MIX) as a replacement of fish meal (FM) in diets on the relative organ weight of broiler chickens ${ }^{1)}$

\begin{tabular}{|c|c|c|c|c|c|c|c|c|c|}
\hline \multirow{2}{*}{ Items $^{2)}(\%)$} & \multicolumn{5}{|c|}{ Inclusion levels of $\mathrm{MIX}^{3)}(\%)$} & \multirow{2}{*}{ SEM } & \multicolumn{3}{|c|}{ p-value ${ }^{4)}$} \\
\hline & 0.00 & 1.25 & 2.50 & 3.75 & 5.00 & & $\mathbf{T}$ & $\mathbf{L}$ & $\mathbf{Q}$ \\
\hline Breast & 21.0 & 20.3 & 21.7 & 20.4 & 20.0 & 0.54 & 0.19 & 0.26 & 0.34 \\
\hline Liver & 3.0 & 2.7 & 2.4 & 2.5 & 2.7 & 0.22 & 0.44 & 0.25 & 0.13 \\
\hline Kidney & 0.6 & 0.7 & 0.5 & 0.6 & 0.6 & 0.04 & 0.20 & 0.55 & 0.56 \\
\hline Small intestine & 3.1 & 3.2 & 3.0 & 3.1 & 3.1 & 0.12 & 0.74 & 0.83 & 0.75 \\
\hline Gizzard & 1.3 & 1.4 & 1.2 & 1.4 & 1.3 & 0.07 & 0.48 & 0.82 & 0.84 \\
\hline
\end{tabular}

SEM, standard error of the mean.

${ }^{1)}$ Data are least squares means of 8 observations per treatment.

${ }^{2)}$ Relative organ weight $=[$ organ weight $(\mathrm{g}) /$ body weight $(\mathrm{g})] \times 100$.

3) MIX was included at replacing levels of $0 \%, 25 \%, 50 \%, 75 \%$, or $100 \%$ with $5.0 \%$ FM in the basal diet.

${ }^{4)} \mathrm{T}$, overall effects of treatments; $L$, linear effects of increasing replacement levels of MIX in diets; Q, quadratic effects of increasing replacement levels of MIX in diets. 
Table 10. Effect of increasing inclusion levels of infertile eggs (IFE) as a replacement of fish meal (FM) in diets on the immune organ index of broiler chickens $^{1)}$

\begin{tabular}{|c|c|c|c|c|c|c|c|c|c|}
\hline \multirow{2}{*}{ Items ${ }^{2)}$} & \multicolumn{5}{|c|}{ Inclusion levels of $\mathrm{IFE}^{3)}(\%)$} & \multirow{2}{*}{ SEM } & \multicolumn{3}{|c|}{ p-value ${ }^{4)}$} \\
\hline & 0.00 & 1.25 & 2.50 & 3.75 & 5.00 & & $\mathrm{~T}$ & $\mathbf{L}$ & $\mathbf{Q}$ \\
\hline Thymus index & 2.62 & 2.36 & 2.96 & 2.38 & 2.30 & 0.379 & 0.72 & 0.60 & 0.56 \\
\hline Bursal index & 1.25 & 1.24 & 1.17 & 1.33 & 1.29 & 0.152 & 0.96 & 0.72 & 0.77 \\
\hline
\end{tabular}

SEM, standard error of the mean.

1) Data are least squares means of 8 observations per treatment.

2) Index = [organ weight $(\mathrm{g}) /$ body weight $(\mathrm{g})] \times 1,000$.

3) IFE was included at replacing levels of $0 \%, 25 \%, 50 \%, 75 \%$, or $100 \%$ with $5.0 \%$ FM in the basal diet.

${ }^{4)} T$, overall effects of treatments; $L$, linear effects of increasing replacement levels of IFE in diets; $Q$, quadratic effects of increasing replacement levels of IFE in diets.

Table 11. Effect of increasing inclusion levels of a mixture of hatchery by-products (MIX) as a replacement of fish meal (FM) in diets on the immune organ index of broiler chickens ${ }^{1)}$

\begin{tabular}{|c|c|c|c|c|c|c|c|c|c|}
\hline \multirow{2}{*}{ Items ${ }^{2)}$} & \multicolumn{5}{|c|}{ Inclusion levels of MIX $^{3)}(\%)$} & \multirow{2}{*}{ SEM } & \multicolumn{3}{|c|}{ p-value $e^{4)}$} \\
\hline & 0 & 25 & 50 & 75 & 100 & & $\mathbf{T}$ & $\mathbf{L}$ & $\mathbf{Q}$ \\
\hline Thymus index & 2.62 & 3.01 & 3.60 & 3.48 & 3.50 & 0.349 & 0.26 & 0.05 & 0.28 \\
\hline Spleen index & 1.54 & 1.22 & 1.43 & 1.53 & 1.85 & 0.270 & 0.60 & 0.29 & 0.26 \\
\hline Bursal index & 1.25 & 1.41 & 1.28 & 1.68 & 1.41 & 0.158 & 0.34 & 0.25 & 0.58 \\
\hline
\end{tabular}

SEM, standard error of the mean.

${ }^{1)}$ Data are least squares means of 8 observations per treatment.

2) Index = [organ weight (g)/body weight $(\mathrm{g})] \times 1,000$.

${ }^{3)}$ MIX was included at replacing levels of $0 \%, 25 \%, 50 \%, 75 \%$, or $100 \%$ with $5.0 \%$ FM in the basal diet.

${ }^{4)}$ T, overall effects of treatments; $L$, linear effects of increasing replacement levels of MIX in diets; Q, quadratic effects of increasing replacement levels of MIX in diets.

\section{Meat quality}

The WHC and TBARS values of breast meat were not influenced by increasing inclusion levels of IFE as a replacement of FM in diets (Table 12). However, increasing inclusion levels of IFE in diets increased (linear, $\mathrm{p}<0.05)$ meat lightness $\left(\mathrm{L}^{*}\right)$ but decreased (linear, $\mathrm{p}<0.05)$ meat redness $\left(\mathrm{a}^{\star}\right)$. The 1-h post- mortem $\mathrm{pH}$ of breast meat was increased (linear, $\mathrm{p}<0.05$ ) by increasing inclusion levels of IFE in diets. In particular, the $\mathrm{pH}$ was significantly greater $(\mathrm{p}<0.05)$ in birds fed diets containing 3.75\% IFE than in birds fed the basal diet. However, the $\mathrm{pH}$ at $24 \mathrm{~h}$ postmortem was not affected by replacing FM with IFE.

Table 12. Effect of increasing inclusion levels of infertile eggs (IFE) as a replacement of fish meal (FM) in diets on meat quality of breast meat of broiler chickens ${ }^{1)}$

\begin{tabular}{|c|c|c|c|c|c|c|c|c|c|}
\hline \multirow{2}{*}{ Items } & \multicolumn{5}{|c|}{ Inclusion levels of IFE' $(\%)$} & \multirow{2}{*}{ SEM } & \multicolumn{3}{|c|}{ p-value $e^{3)}$} \\
\hline & 0.00 & 1.25 & 2.50 & 3.75 & 5.00 & & $\mathrm{~T}$ & $\mathbf{L}$ & $\mathbf{Q}$ \\
\hline \multicolumn{10}{|l|}{ Meat color } \\
\hline$L^{*}$ & 45.0 & 46.2 & 46.4 & 47.3 & 48.9 & 0.98 & 0.09 & $<0.05$ & 0.69 \\
\hline$a^{*}$ & 4.5 & 3.4 & 3.3 & 3.8 & 2.3 & 0.54 & 0.11 & $<0.05$ & 0.92 \\
\hline$b^{*}$ & 11.5 & 11.9 & 11.3 & 12.2 & 11.7 & 0.78 & 0.94 & 0.76 & 0.90 \\
\hline \multicolumn{10}{|l|}{$\mathrm{pH}$} \\
\hline $1 \mathrm{~h}$ & $6.23^{b}$ & $6.36^{\mathrm{ab}}$ & $6.39^{\mathrm{ab}}$ & $6.54^{\mathrm{a}}$ & $6.40^{\mathrm{ab}}$ & 0.067 & $<0.05$ & $<0.05$ & 0.09 \\
\hline $24 \mathrm{~h}$ & 6.03 & 5.94 & 5.96 & 6.05 & 5.96 & 0.037 & 0.18 & 0.85 & 0.59 \\
\hline WHC & 72.3 & 78.2 & 75.5 & 75.9 & 72.4 & 3.72 & 0.77 & 0.86 & 0.27 \\
\hline TBARS (mg MDA/kg) & 0.33 & 0.33 & 0.31 & 0.31 & 0.31 & 0.012 & 0.49 & 0.19 & 0.74 \\
\hline
\end{tabular}

SEM, standard error of the mean; L*, lightness; $a^{\star}$, redness; b*, yellowness; WHC, water holding capacity; TBARS, thiobarbituric acid-reactive substances; MDA, malondialdehyde.

1) Data are least squares means of 8 observations per treatment.

2) IFE was included at replacing levels of $0,25,50,75$, or $100 \%$ with $5.0 \%$ FM in the basal diet.

3) $T$, overall effects of treatments; $L$, linear effects of increasing replacement levels of IFE in diets; Q, quadratic effects of increasing replacement levels of IFE in diets.

$a, b$ Means with different superscripts within a row are different $(p<0.05)$. 
Table 13. Effect of increasing inclusion levels of a mixture of hatchery by-products (MIX) as a replacement of fish meal (FM) in diets on meat quality of breast meat of broiler chickens ${ }^{1)}$

\begin{tabular}{|c|c|c|c|c|c|c|c|c|c|}
\hline \multirow{2}{*}{ Items } & \multicolumn{5}{|c|}{ Inclusion levels of $\mathrm{MIX}^{2)}(\%)$} & \multirow{2}{*}{ SEM } & \multicolumn{3}{|c|}{ p-value ${ }^{3)}$} \\
\hline & 0.00 & 1.25 & 2.50 & 3.75 & 5.00 & & $\mathbf{T}$ & $\mathbf{L}$ & Q \\
\hline \multicolumn{10}{|l|}{ Meat color } \\
\hline$L^{*}$ & 45.0 & 46.7 & 46.1 & 45.8 & 45.6 & 0.92 & 0.77 & 0.90 & 0.31 \\
\hline$a^{*}$ & 4.5 & 4.2 & 4.4 & 4.0 & 3.6 & 0.54 & 0.79 & 0.25 & 0.72 \\
\hline$b^{*}$ & 11.5 & 12.6 & 12.3 & 12.0 & 11.8 & 0.59 & 0.68 & 0.97 & 0.22 \\
\hline \multicolumn{10}{|l|}{$\mathrm{pH}$} \\
\hline $1 \mathrm{~h}$ & 6.23 & 6.36 & 6.39 & 6.34 & 6.40 & 0.051 & 0.14 & $<0.05$ & 0.25 \\
\hline $24 \mathrm{~h}$ & 6.03 & 5.92 & 5.97 & 5.91 & 5.91 & 0.036 & 0.08 & $<0.05$ & 0.48 \\
\hline WHC & 72.3 & 75.2 & 74.5 & 73.3 & 74.1 & 3.50 & 0.98 & 0.87 & 0.72 \\
\hline TBARS (mg MDA/kg) & 0.33 & 0.34 & 0.32 & 0.30 & 0.30 & 0.010 & 0.06 & $<0.05$ & 0.41 \\
\hline
\end{tabular}

SEM, standard error of the mean; L*, lightness; $a^{*}$, redness; $b^{*}$, yellowness; WHC, water holding capacity; TBARS, thiobarbituric acid-reactive substances; MDA, malondialdehyde.

1) Data are least squares means of 8 observations per treatment.

${ }^{2)} \mathrm{MIX}$ was included at replacing levels of $0 \%, 25 \%, 50 \%, 75 \%$, or $100 \%$ with $5.0 \% \mathrm{FM}$ in the basal diet.

${ }^{3)}$ T, overall effects of treatments; $L$, linear effects of increasing replacement levels of MIX in diets; $Q$, quadratic effects of increasing replacement levels of MIX in diets.

Increasing inclusion levels of MIX in diets did not influence meat color and WHC of breast meat (Table 13). However, increasing inclusion levels of MIX in diets increased (linear, $\mathrm{p}<0.05) \mathrm{pH}$ at $1 \mathrm{~h}$ postmortem but decreased (linear, $\mathrm{p}<0.05$ ) $\mathrm{pH}$ at $24 \mathrm{~h}$ postmortem. In addition, increasing inclusion levels of MIX in diets decreased (linear, $\mathrm{p}<0.05$ ) TBARS values of breast meat.

Meat color is one of the important factors affecting consumers' preferences with regard to broiler meat [6]. For broiler breast meat, $\mathrm{L}^{*}$ values of 42 to 50 and $\mathrm{a}^{*}$ values of 1.9 to 5.3 have been widely reported [30-32]. The $\mathrm{L}^{\star}$ and $\mathrm{a}^{\star}$ values observed in this experiment fell within the quantitative range although the linear increase in $\mathrm{L}^{*}$ value and linear decrease in $\mathrm{a}^{*}$ value were observed with increasing inclusion levels of IFE in this experiment. It is not clear whether some specific chemical compounds in eggs (i.e., IFE) may affect breast meat colors, as no such effect has been reported previously in broiler chickens. However, it appears that consumers would be unable to distinguish HBP-fed birds from FM-fed birds on the basis of meat color.

The low $\mathrm{pH}$ value of breast meat is often associated with low meat quality [33]. In the current study, the $\mathrm{pH}$ values at $1 \mathrm{~h}$ postmortem were increased (linear, $\mathrm{p}<0.05$ ) by increasing inclusion levels of both IFE and MIX, whereas $\mathrm{pH}$ values at $24 \mathrm{~h}$ postmortem were decreased (linear, $\mathrm{p}<0.05$ ) with increasing inclusion levels of MIX. Postmortem $\mathrm{pH}$ is dependent primarily on the amount of glycogen in the muscle and the rate of its degradation to lactic acid [34]. However, it is unclear whether some specific chemical compounds in IFE and MIX may influence the concentration or degradation rate of glycogen in the muscle. However, all $\mathrm{pH}$ values of breast meat observed in this experiment fell within the normal range from 6.20 to 6.54 for $1 \mathrm{~h}$ postmortem $[21,22]$ and from 5.85 to 6.34 for 24 postmortem $[21,32]$, indicating that replacement of FM with IFE and MIX exerts no adverse effects on the postmortem $\mathrm{pH}$ of breast meat.

The TBARS value is used as an indicator of lipid peroxidation, and thus meat with low TBARS values is considered less oxidized [6]. Interestingly, we found that increasing replacement of FM with both IFE and MIX tended to decrease TBARS values of breast meat although the significance was only detected for broiler chickens fed diets containing MIX. Thus, replacement of FM with IFE and MIX is likely to decrease lipid peroxidation in breast meat. This observation is likely caused by the fact that FM contains a greater amount of polyunsaturated fatty acids as compared to other animal protein sources [35], as it is well-known that polyunsaturated fatty acids are more prone to oxidation than saturated fatty acids [36]. Therefore, one potential benefit of replacing FM with IFE or MIX may be the improvement in lipid stability of breast meat, which can increase the shelf-life of breast meat. It should be noted, however, that all TBARS values measured in this experiment fell within the normal range from 0.18 to 1.32 for $7 \mathrm{~d}$ postmortem [21,37]. Therefore, it appears that neither FM nor both HBPs (i.e., IFE and MIX) have considerable effects on lipid stability of the breast meat.

\section{Tibia characteristics}

The tibia characteristics, including concentrations of ash, $\mathrm{Ca}$, and $\mathrm{P}$, and breaking strength were not affected by increasing inclusion levels of IFE or MIX (Tables 14, 15). This is likely related to the fact that all diets were formulated to contain the identical concentrations of minerals such as $\mathrm{Ca}$ and P. In addition, minerals such as $\mathrm{Ca}$ and $\mathrm{P}$ in the IFE and MIX are mostly derived from the ES, and it has been reported that $\mathrm{Ca}$ and $\mathrm{P}$ present in the ES are highly digestible and utilizable 
Table 14. Effect of increasing inclusion levels of infertile eggs (IFE) as a replacement of fish meal (FM) in diets on the tibia characteristics of broiler chickens $^{1)}$

\begin{tabular}{|c|c|c|c|c|c|c|c|c|c|}
\hline \multirow{2}{*}{ Items } & \multicolumn{5}{|c|}{ Inclusion levels of IFE") $(\%)$} & \multirow{2}{*}{ SEM } & \multicolumn{3}{|c|}{ p-value ${ }^{3)}$} \\
\hline & 0.00 & 1.25 & 2.50 & 3.75 & 5.00 & & $\mathbf{T}$ & $\mathbf{L}$ & $\mathbf{Q}$ \\
\hline Tibia ash (\%) & 52.7 & 52.0 & 52.1 & 52.3 & 52.7 & 0.50 & 0.76 & 0.87 & 0.20 \\
\hline Tibia phosphorus (\%) & 16.1 & 16.1 & 17.2 & 15.5 & 15.9 & 1.11 & 0.84 & 0.76 & 0.62 \\
\hline Tibia breaking strength $(\mathrm{kg})$ & 35.3 & 38.6 & 34.3 & 41.5 & 36.0 & 2.87 & 0.40 & 0.64 & 0.59 \\
\hline
\end{tabular}

SEM, standard error of the mean.

1) Data are least squares means of 8 observations per treatment.

2) IFE was included at replacing levels of $0 \%, 25 \%, 50 \%, 75 \%$, or $100 \%$ with $5.0 \%$ FM in the basal diet.

${ }^{3)} T$, overall effects of treatments; $L$, linear effects of increasing replacement levels of IFE in diets; $Q$, quadratic effects of increasing replacement levels of IFE in diets.

Table 15. Effect of increasing inclusion levels of a mixture of hatchery by-products (MIX) as a replacement of fish meal (FM) in diets on the tibia characteristics of broiler chickens ${ }^{1)}$

\begin{tabular}{|c|c|c|c|c|c|c|c|c|c|}
\hline \multirow{2}{*}{ Items } & \multicolumn{5}{|c|}{ Inclusion levels of $\mathrm{MIX}^{2)}(\%)$} & \multirow{2}{*}{ SEM } & \multicolumn{3}{|c|}{ p-value ${ }^{3)}$} \\
\hline & 0.00 & 1.25 & 2.50 & 3.75 & 5.00 & & $\mathbf{T}$ & $\mathbf{L}$ & $\mathbf{Q}$ \\
\hline Tibia ash (\%) & 52.7 & 53.6 & 52.3 & 53.7 & 52.4 & 0.52 & 0.18 & 0.81 & 0.41 \\
\hline Tibia phosphorus (\%) & 16.1 & 15.2 & 15.6 & 15.0 & 15.0 & 1.01 & 0.92 & 0.45 & 0.82 \\
\hline Tibia breaking strength (kg) & 35.3 & 40.4 & 39.0 & 37.8 & 42.8 & 2.47 & 0.29 & 0.12 & 0.98 \\
\hline
\end{tabular}

SEM, standard error of the mean.

1) Data are least squares means of 8 observations per treatment.

2) MIX was included at replacing levels of $0 \%, 25 \%, 50 \%, 75 \%$, or $100 \%$ with $5.0 \%$ FM in the basal diet.

${ }^{3)} \mathrm{T}$, overall effects of treatments; L, linear effects of increasing replacement levels of MIX in diets; Q, quadratic effects of increasing replacement levels of MIX in diets.

by poultry [2].

\section{CONCLUSION}

Replacement of FM with HBPs as IFE and MIX up to 5.0\% in diets has no adverse effects on growth performance, plasma measurements, relative organ weight, immune organ index, breast meat quality, and tibia characteristics of broiler chickens, provided that diets are formulated with appropriate energy and nutrient concentrations. One potential benefit of replacing FM with IFE or MIX may be the improvement in lipid stability of broiler meat by decreasing concentrations of polyunsaturated fatty acids. Therefore, both IFE and MIX can serve as economically feasible alternatives to FM as a protein source in broiler diets.

\section{CONFLICT OF INTEREST}

We certify that there is no conflict of interest with any financial organization regarding the material discussed in the manuscript.

\section{ACKNOWLEDGMENTS}

This research was carried out with the support of the Coopera- tive Research Program for Agriculture Science and Technology Development (Project No. PJ01252804), Rural Development Administration, Republic of Korea. This research was also supported by the Chung-Ang University Graduate Research Scholarship in 2020.

\section{REFERENCES}

1. Abiola SS, Onunkwor EK. Replacement value of hatchery waste meal for fish meal in layer diets. Bioresour Technol 2004;95:103-6. https://doi.org/10.1016/j.biortech.2004.02. 001

2. Choi HS, Park GH, Kim JH, Ji SY, Kil DY. Determination of calcium and phosphorus utilization in various hatchery byproducts for broiler chickens. Korean J Agric Sci 2019;46:3618. https://doi.org/10.7744/kjoas.20190023

3. Ratriyanto A, Suprayogui WPS, Atikah R. Infertile egg powder as a potential feedstuff for starter broilers. IOP Conf Ser: Earth Environ Sci 2020;518:012005. https://doi.org/10.1088/17551315/518/1/012005

4. Aviagen. Ross 308 broiler: nutrition specifications. Huntsville, AL, USA: Aviagen Inc; 2018. http://en.aviagen.com/

5. Chen HL, Li DF, Chang BY, Gong LM, Dai JG, Yi GF. Effects of Chinese herbal polysaccharides on the immunity and growth performance of young broilers. Poult Sci 2003;82: 
364-70. https://doi.org/10.1093/ps/82.3.364

6. Lee SJ, Lee SY, Kim GD, GB Kim, SK Jin, SJ Hur. Effects of self-carbon dioxide-generation material for active packaging on $\mathrm{pH}$, water-holding capacity, meat color, lipid oxidation and microbial growth in beef during cold storage. J Sci Food Agric 2017;97:3642-8. https://doi.org/10.1002/jsfa.8223

7. Watson BC, Matthews JO, Southern LL, Shelton JL. The effects of phytase on growth performance and intestinal transit time of broilers fed nutritionally adequate diets and diets deficient in calcium and phosphorus. Poult Sci 2006;85: 493-7. https://doi.org/10.1093/ps/85.3.493

8. Woyengo TA, Emiola IA, Kim IH, Nyachoti CM. Bioavailability of phosphorus in two cultivars of pea for broiler chicks. Asian-Australas J Anim Sci 2016;29:396-403. https://doi.org/ 10.5713/ajas.15.0299

9. Kurtoğlu F, Kurtoğlu V, Celik I, Kececi T, Nizamlioğlu M. Effects of dietary boron supplementation on some biochemical parameters, peripheral blood lymphocytes, splenic plasma cells and bone characteristics of broiler chicks given diets with adequate or inadequate cholecalciferol (vitamin $\mathrm{D}_{3}$ ) content. Br Poult Sci 2005;46:87-96. https://doi.org/10.1080/0007166 0400024001

10. Shaw AL, Blake JP, Moran ET. Effects of flesh attachment on bone breaking and of phosphorus concentration on performance of broilers hatched from young and old flocks. Poult Sci 2010;89:295-302. https://doi.org/10.3382/ps.2009-00402

11. Abiola SS, Radebe NE, Westhuizen CVD, Umesiobi DO. Whole hatchery waste meal as alternative protein and calcium sources in broiler diets. Archiv Zootec 2012;61:229-34.

12. Dhaliwal APS, Shingari BK, Sapra KL. Chemical composition of hatchery waste. Pak Vet J 1997;17:168-70.

13. Rasool S, Rehan M, Haq A, Alam MZ. Preparation and nutritional evaluation of hatchery waste meal for broilers. AsianAustralas J Anim Sci 1999;12:554-7. https://doi.org/10.5713/ ajas.1999.554

14. Beski SSM, Swick RA, Iji PA. Specialized protein products in broiler chicken nutrition: a review. Anim Nutr 2015;1:4753. https://doi.org/10.1016/j.aninu.2015.05.005

15. Piotrowska A, Burlikowska K, Szymeczko R. Changes in blood chemistry in broiler chickens during the fattening period. Folia Biol 2011;59:183-7. https://doi.org/10.3409/fb59_3-4. 183-187

16. Azadmanesh V, Jahanian R. Effect of supplemental lipotropic factors on performance, immune responses, serum metabolites and liver health in broiler chicks fed on high-energy diets. Anim Feed Sci Technol 2014;195:92-100. https://doi.org/10. 1016/j.anifeedsci.2014.06.004

17. Adriani L, Nugraha P, Marin M. The effect of granting fermented milk, fermented soy milk, and the combination against creatinine and blood glucose levels on broiler. AgroLife Sci J 2017;6:9-15.

18. Mehdipour M, Shargh MS, Dastar B, Hassani S. Effects of different levels of hatchery wastes on the performance, carcass and tibia ash and some blood parameters in broiler chicks. Pak J Biol Sci 2009;12:1272-6. https://doi.org/10.3923/pjbs. 2009.1272.1276

19. Awad WA, Ghareeb K, Abdel-Raheem S, Böhm J. Effects of dietary inclusion of probiotic and synbiotic on growth performance, organ weights, and intestinal histomorphology of broiler chickens. Poult Sci 2009;88:49-56. https://doi.org/10. 3382/ps.2008-00244

20. Elaroussi MA, Mohamed FR, Elgendy MS, El Barkouky EM, Abdou AM, Hatab MH. Ochratoxicosis in broiler chickens: functional and histological changes in target organs. Int J Poult Sci 2008;7:414-22. https://doi.org/10.3923/ijps.2008.414.422

21. Goo D, Kim JH, Choi HS, Park GH, Han GP, Kil DY. Effect of stocking density and sex on growth performance, meat quality, and intestinal barrier function in broiler chickens. Poult Sci 2019;98:1153-60. https://doi.org/10.3382/ps/pey491

22. Wang JP, Lee JH, Yoo JS, Cho JH, Kim HJ, Kim IH. Effects of phenyllactic acid on growth performance, intestinal microbiota, relative organ weight, blood characteristics, and meat quality of broiler chicks. Poult Sci 2010;89:1549-55. https:// doi.org/10.3382/ps.2009-00235

23. Sacranie A, Svihus B, Denstadli V, Moen B, Iji PA, Choct $M$. The effect of insoluble fiber and intermittent feeding on gizzard development, gut motility, and performance of broiler chickens. Poult Sci 2012;91:693-700. https:/doi.org/ 10.3382/ps.2011-01790

24. Kheravii SK, Swick RA, Choct M, Wu S-B. Dietary sugarcane bagasse and coarse particle size of corn are beneficial to performance and gizzard development in broilers fed normal and high sodium diets. Poult Sci 2017;96:4006-16. https:// doi.org/10.3382/ps/pex225

25. Pearse G. Normal structure, function and histology of the thymus. Toxicol Pathol 2006;34:504-14. https://doi.org/10. 1080/01926230600865549

26. Nagy N, Olah I. Experimental evidence for the ectodermal origin of the epithelial anlage of the chicken bursa of Fabricius. Development 2010;137:3019-23. https://doi.org/10.1242/ dev.055194

27. Guo Y, Jiang R, Su A, et al. Identification of genes related to effects of stress on immune function in the spleen in a chicken stress model using transcriptome analysis. Mol Immunol 2020;124:180-9. https://doi.org/10.1016/j.molimm.2020.06. 004

28. Attia YA, Al-Khalaifah H, Ibrahim MS, Abd Al-Hamid AE, Al-Harthi MA, El-Naggar A. Blood hematological and biochemical constituents, antioxidant enzymes, immunity and lymphoid organs of broiler chicks supplemented with propolis, bee pollen and mannan oligosaccharides continuously or intermittently. Poult Sci 2017;96:4182-92. https://doi.org/10. 3382/ps/pex173

29. Chen C, Li J, Zhang H, et al. Effects of a probiotic on the 
growth performance, intestinal flora, and immune function of chicks infected with Salmonella pullorum. Poult Sci 2020; 99:5316-23. https://doi.org/10.1016/j.psj.2020.07.017

30. Chen Y, Gu Y, Zhao H, Zhang H, Zhou Y. Effects of graded levels of dietary squalene supplementation on the growth performance, plasma biochemical parameters, antioxidant capacity, and meat quality in broiler chickens. Poult Sci 2020; 99:5915-24. https://doi.org/10.1016/j.psj.2020.08.042

31. Chang Q, Lu Y, Lan R. Chitosan oligosaccharide as an effective feed additive to maintain growth performance, meat quality, muscle glycolytic metabolism, and oxidative status in yellowfeather broilers under heat stress. Poult Sci 2020;99:4824-31. https://doi.org/10.1016/j.psj.2020.06.071

32. Kim HJ, Kim HJ, Jeon JJ, et al. Comparison of the quality characteristics of chicken breast meat from conventional and animal welfare farms under refrigerated storage. Poult Sci 2020;99:1788-96. https://doi.org/10.1016/j.psj.2019.12. 009

33. Swatland HJ. How $\mathrm{pH}$ causes paleness or darkness in chicken breast meat. Meat Sci 2008;80:396-400. https://doi.org/10. 1016/j.meatsci.2008.01.002

34. Duclos MJ, Berri C, Le Bihan-Duval E. Muscle growth and meat quality. J Appl Poult Res 2007;16:107-12. https://doi. org/10.1093/japr/16.1.107

35. The French National Institute for Agricultural Research (INRA). Tables of composition and nutritional value of feed materials. Wageningen, The Netherlands: Wageningen Academic Publishers; 2004.

36. Valentini J, Da Silva AS, Fortuoso BF, et al. Chemical composition, lipid peroxidation, and fatty acid profile in meat of broilers fed with glycerol monolaurate additive. Food Chem 2020;330:127187. https://doi.org/10.1016/j.foodchem.2020. 127187

37. Vaithiyanathan S, Naveena BM, Muthukumar M, et al. Biochemical and physicochemical changes in spent hen breast meat during postmortem aging. Poult Sci 2008;87:180-6. https://doi.org/10.3382/ps.2007-00068

38. Choi HS, Goo D, Pitargue FM, et al. Determination of metabolizable energy values for various hatchery by-products for broiler chickens. In: Proceedings of Korean Society of Poultry Science 2017; 2017 Nov 9-10; Jeonbuk, KR. Gangwon, KR: Korean Society of Poultry Science; 2017. 129 p.

39. Latimer GW; AOAC International. Official methods of analysis of AOAC International. 19th ed. Gaithersburg, MD, USA: AOAC International; 2012 